\section{From a Nobel Perspective}

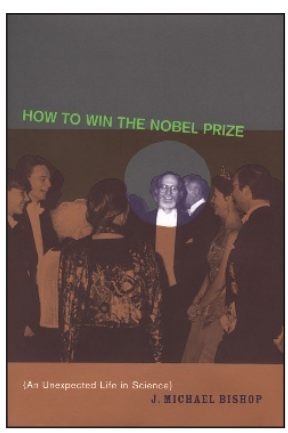

\section{How to Win the Nobel Prize: An Unexpected Life in Science}

\section{by J Michael Bishop}

Harvard University Press, $\$ 27.95$

320 pp. hardcover

ISBN 0674008804, 2003

\section{Reviewed by Paul Greengard}

There are many reasons to read this splendid book. Learning "how to win the Nobel Prize," the tongue-in-cheek title of this autobiography, is not one of them. Mike Bishop, together with Harold Varmus, jointly received the Nobel Prize in 1989 for discovering the cellular origin of retroviral oncogenes.

Bishop's book is a series of five quasi-independent chapters. The first, an essay on 'Nobelology', describes Alfred Nobel, the eccentric genius who invented dynamite and bequeathed his vast fortune to establish the Nobel Prizes. The reader of this chapter will learn about Nobel, the battle his family and much of Sweden's power structure waged to invalidate his will, the ceremony and banquet held each year on 10 December, Nobel's birthday, the procedures by which Nobel laureates are selected, errors of omission and commission made by various Nobel committees and some of the effects on Bishop of being the recipient of this nod from Stockholm.

One Nobel laureate has reportedly described the Nobel Prize as "the Prize that keeps on giving." In the book, Bishop recounts an amusing anecdote that exemplifies this statement. Bishop and Varmus were invited to throw out the first pitch in one of the games of the 1989 World Series. The invitation meant a great deal to Bishop-apparently more than the Nobel itself-because he is a fanatical fan of the San Francisco Giants, having inexplicably forgiven them for abandoning New York (does he realize the Giants may now be renegotiating with another city?). The legendary Willie Mays was to throw out the first pitch of the third game of the World Series; Mike and Harold were to throw out the first pitch of the fourth game (I am still trying to understand how two individuals could simultaneously throw a single baseball 60 feet).

Before the game, however, an earthquake intervened and the first-pitch list was revised to honor 20 "heroes of the earthquake" at the third game. As a result, Mays was moved from the third game to the fourth and the Bishop/Varmus team to the fifth. The Giants

The author, a Nobel laureate in Medicine, is Vincent Astor professor of neuroscience at The Rockefeller University, 1230 York Avenue, New York, New York 10021, USA. e-mail: greengd@mail.rockefeller.edu had already lost two games of seven and Mike feared that there would not be a fifth game. He therefore

"...protested the change to the then commissioner of baseball, Fay Vincent, and asked instead that Harold and I be allowed to share the mound with Willie Mays at game four. There was a short pause and then the commissioner said, 'Doc, get real.' The Giants fell in four. Harold and I had to settle for a consolation prize: the first pitch at a Giants-Dodgers game the following season."

Compassion, please, dear reader: it is not easy being a Nobel laureate.

The second chapter is an autobiography of Bishop and his long journey from a two-room schoolhouse in rural Pennsylvania to the King of Sweden's dinner table. One of the most amusing vignettes in this chapter concerns Mike's choice of medical school. His chemistry advisor in college suggested that he consider Harvard.

'Where is that?' I asked. 'In Boston somewhere, I think,' was his response ...I wrote a letter to Harvard, explaining that I was having difficulty deciding between it and the University of Pennsylvania. Could I come and visit? Years later, the dean of students at Harvard told me that my letter had been posted in the dean's office for the amusement of the staff. Thus did I learn the measure of institutional arrogance.

The next two chapters are exemplary in explaining a highly specialized area of medical research in a way that is comprehensible to a lay audience and still of substantial interest to scientists in other fields of biomedical research. One of these chapters provides a short history of infectious diseases (in which the reader learns that George Bernard Shaw called vaccination "a particularly filthy piece of witchcraft"). The other addresses cancer research and includes an explanation of the advances made by Bishop and Varmus in the field of oncology.

Finally, Bishop, in a tour de force, describes and deplores the increasing gap between the scientific community and the general public, including government leaders. Indeed, the phenomenal advances made in all fields of science in recent decades have had incalculable effects-both good and bad-on the world. More important, biomedical discoveries to come in the not-too-distant future have potential for the most amazing benefits and the most horrendous abuses. The acerbic debate about stem cell research provides a clear-cut example of the issues involved. There is a major need for improved education of the general public by the scientific community. Bishop describes his experience with the American public's disappointment, distrust, suspicion, disdain and ignorance of scientific enterprise, surely one of the jewels of this nation.

Michael Bishop is a highly erudite individual, broadly versed in the medical sciences, social sciences and humanities. He is also an exceptionally talented and lucid writer. His broad interests and knowledge and his excellent expository skills make this book an informative and delightful read. 